\title{
ORIGINAL ARTICLE \\ Frequency of Anatomical Variants of Paranasal Sinuses (PNS) on Computed Tomography (CT)
}

\author{
MUSTAFA ALI SIDDIQUI ${ }^{1}$, MUHAMMAD AMIN², ATQA FIRDOUS ${ }^{3}$, HAMMAD AHMAD SAQIB $^{4}$, SUMERA NIGHAT 5 , \\ ZIA UL ISLAM ${ }^{6}$, M. M. KHAN ${ }^{7}$ \\ ${ }^{1}$ Professor Radiology CPEIC Multan \\ ${ }^{2}$ Assistant Professor Radiology, Children Hospital and Institute of Child Health Multan \\ ${ }^{3}$ Assistant Professor Radiology Multan Medical \& Dental College, Multan. \\ ${ }^{4}$ Assistant Professor Radiology Ch. Parvez Elahi Institute of Cardiology, Multan. \\ ${ }^{5}$ Assistant Professor Radiology Bakhatawar Ameen Medical College Multan \\ ${ }^{6}$ Assistant Professor Radiology Multan Medical \& Dental College, Multan \\ ${ }^{7}$ Professor NMDC \\ Correspondence to: Prof. Dr. Mustafa Ali Siddiqui, Email: drmusafa.ali148@gmail.com, Cell: 03040519600
}

\begin{abstract}
Background: The para nasal sinuses be collection of air filled spaces adjoining the nasal cavity. Para nasal sinuses build up as of the primitive choana at 25-28 weeks of gestation. Three projections ascend from the lateral wall of the nose and work as the commencement of the growth of the para nasal sinuses. The Frequency of Anatomical Variants of Para nasal Sinuses (PNS) may be illustrated on Computed Tomography (CT) by using double slice CT machine.

Aim: To reveal the anatomy of the para nasal sinuses as shown on the CT along with point out the variants lead to chronic sinusitis and escort obstacles in sino nasal operations.

Methodology: This study was conducted in Ibnae-e Sieena Hospital and MMDC Multan during September 2019 to December 2019. In 50 patients without para nasal sinus diseases symptoms, head computed tomography studies were carried out after having consent from them and IRB. Para nasal sinuses coronal sections were taken. The CT studies were performed by using Dual Source multi slice CT Scanner.

Results: 50 participants included in the study, 25 men with 25 women. Out of them, 22 having anatomical variants were noticed. Most common anatomical variants found were pneumatisation of center nasal turbinates (30\%) then agger nasi cells $25 \%$, Haller's cells $20 \%$, along with septal deviation $13 \%$ and sphenoid sinus septation (12\%).

Conclusion: This study shows that nasal cavity and para nasal sinuses anatomical variations are common. For the radiologic analysis of the para nasal sinuses, as of diagnosis of the pre and post -surgical evaluation and sinonasal lesions, CT is the gold standard procedure. It can outline and explain the anatomical variants in para nasal sinuses. CT not only detect the lesion to vital constitutions which lined the para nasal sinuses but also repeated lesions that extra mural cells. CT of the para nasal sinuses has vital importance and should be passably analyze before FESS.

Keywords: Para nasal sinuses, Computed tomography, Nasal turbinate, Ostiomeatal complex
\end{abstract}

\section{INTRODUCTION}

The para nasal sinuses be collection of air filled spaces adjoining the nasal cavity. Para nasal sinuses build up as of the primitive choana at 25-28 weeks of gestation ${ }^{1,2 . .}$. Three projections ascend from the lateral wall of the nose and work as the commencement of the growth of the para nasal sinuses. The Frequency of Anatomical Variants of Para nasal Sinuses (PNS) may be illustrated on Computed Tomography (CT) by using double slice CT machine. The MS and ES are aerated at birth, while the sphenoid sinuses and frontal sinuses are pneumatized at about the 2nd and 6 th year of life respectively. $3,4,5$ The sinuses reach the adult size at adolescent age. ${ }^{6,7,8}$

Standard paranasal sinus radiograph can readily demonstrate the MS or FS diseases but incompletely outlines ES due to overlapping of structures. ${ }^{9,10,11}$

The growth of the para nasal sinuses particularly the ethmoid labyrinth is related to anatomical disparities ${ }^{12,13,14}$. This study was conducted to reveal the anatomy of

Received on 12-01-2021

Accepted on 02-05-2021 the para nasal sinuses as shown on the CT along with point out the variants lead to chronic sinusitis and escort obstacles in sino nasal operations.

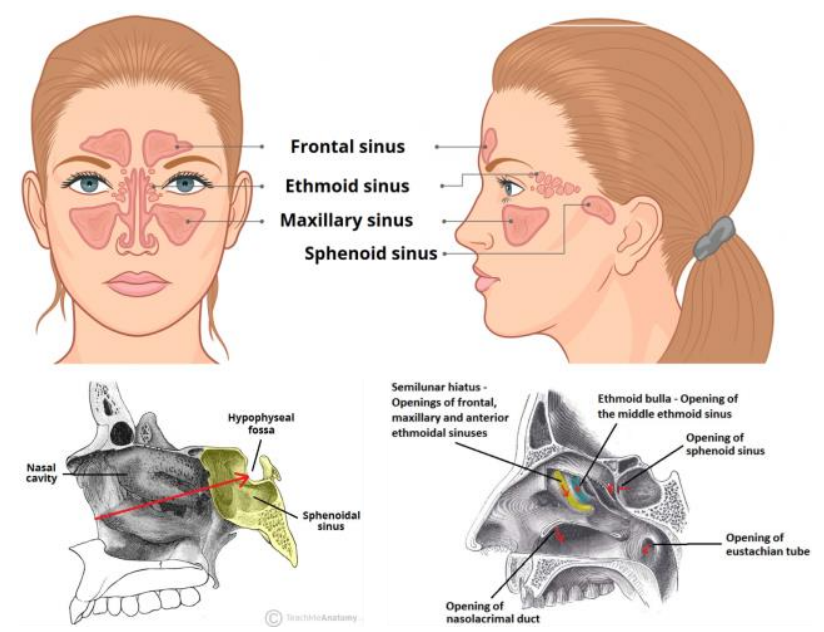



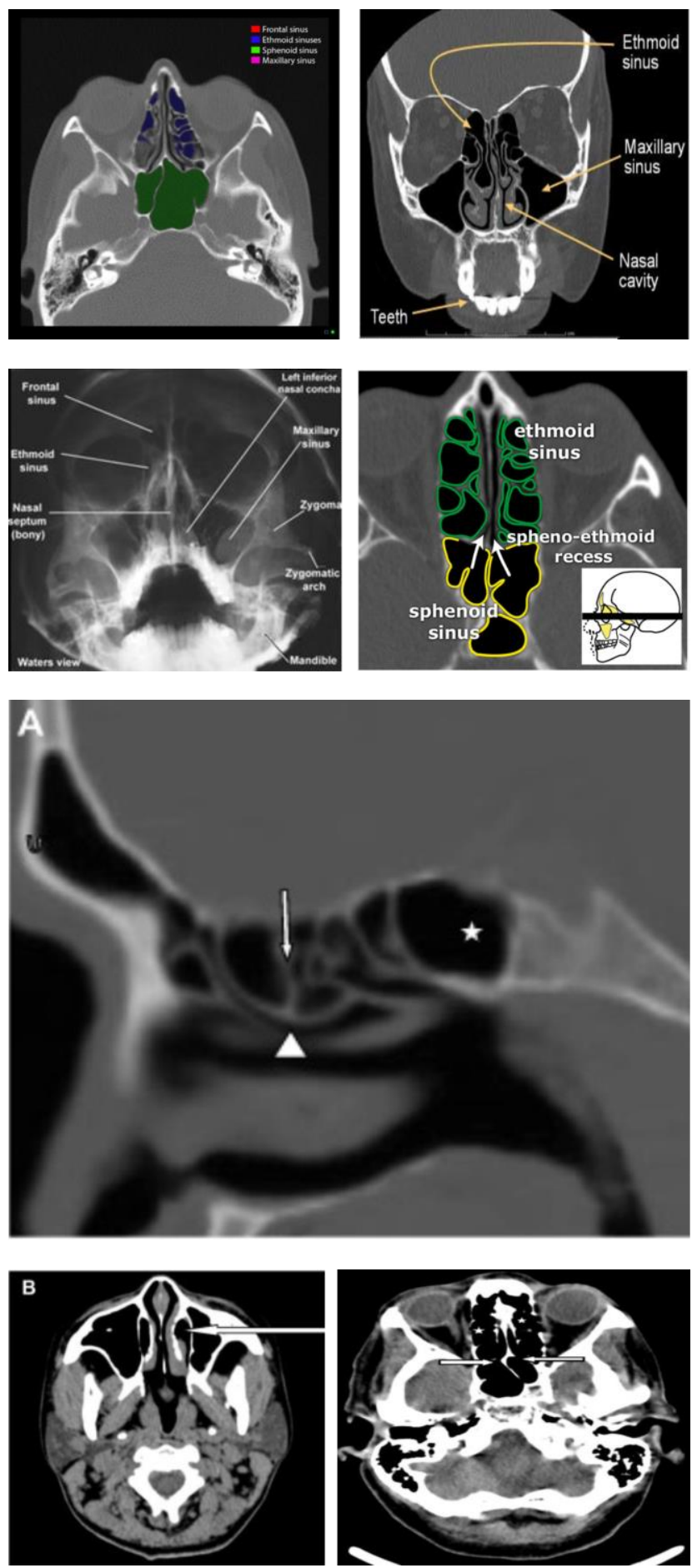

\section{METHODOLOGY}

This study was conducted in Ibnae-e Sieena Hospital and MMDC Multan during September 2019 to December 2019. In 50 patients without para nasal sinus diseases symptoms, head computed tomography studies were carried out after having consent from them and IRB. Para nasal sinuses coronal sections were taken. The CT studies were performed by using Dual Source multi slice CT Scanner.

\section{RESULTS}

Fifty participants included in the study, 25 men with 25 women. Out of them, 22 having anatomical variants were noticed. Most common anatomical variants found were pneumatisation of center nasal turbinates (30\%) then agger nasi cells $25 \%$, Haller's cells $20 \%$, along with septal deviation $13 \%$ and sphenoid sinus septation (12\%).

\section{DISCUSSION}

Maxillary sinus variants: Maxillary sinus irregularity in size and shape is common. MS pneumatisation may be extended to the palatine recess and alveolar recess. Septations of the maxillary sinuses may also be observed. Accessory ostiums may be present that is in general solitary, and also many. AMO be there inherited. It may be due to sino nasal ailments. ${ }^{15,16,17,18,}$

Nasal turbinates variants: Middle turbinate for pneumatisation is mostly while the ST and the IT are fewer. Their occurrence were here found as $30 \%$ Asruddin et al. ${ }^{7}$ Mamitha et al. ${ }^{8}$ Zinreich et al. ${ }^{2}$ and Weinberger et al. ${ }^{9}$ reported occurrence of $28 \%, 26 \%$, and $14 \%$ respectively. High occurance was stated by Aramani et al. ${ }^{10}$ Perez-Pinas et al. ${ }^{11}$ and Scribano et al. ${ }^{12}$ who got $53.7 \%, 73 \%$ and $67 \%$ respectively.

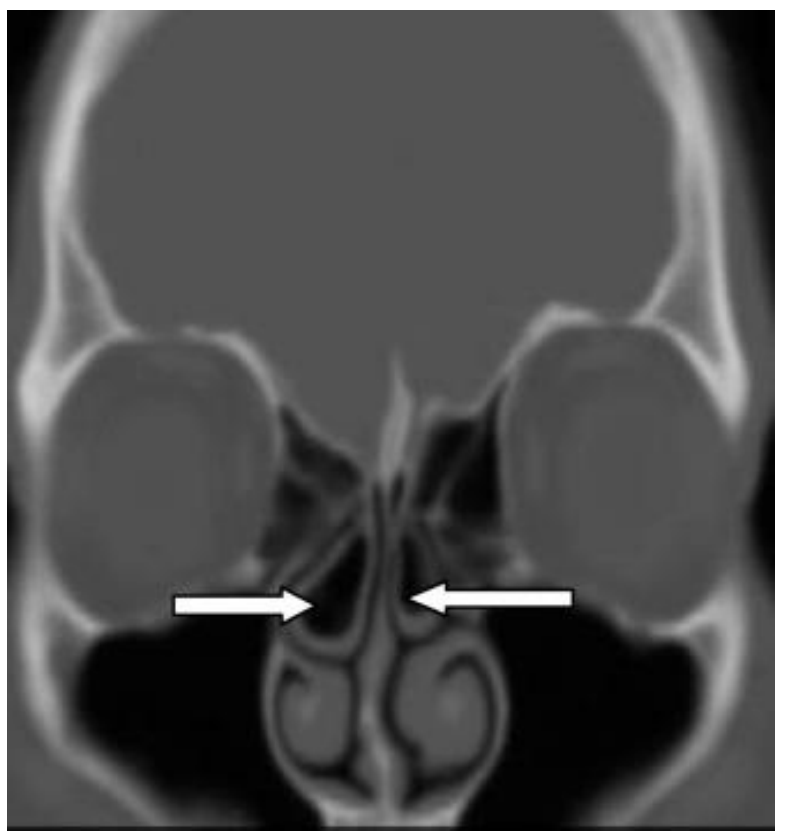

Arrow shows the bilateral middle turbinate pneumatisation

Irregular bend of the MT to the midline may occur that's identified as the paradoxical middle turbinates. Extra or lesser middle turbinate septation may also occur but not found here. Inferior turbinates anatomical variations are rare.

\section{CONCLUSION}

This study shows that nasal cavity and para nasal sinuses anatomical variations are common. For the radiologic analysis of the para nasal sinuses, as of diagnosis of the 
pre and post -surgical evaluation and sino-nasal lesions, $\mathrm{CT}$ is the gold standard procedure. It can outline and explain the anatomical variants in para nasal sinuses. CT not only detect the lesion to vital constitutions which lined the para nasal sinuses but also repeated lesions that extra mural cells. CT of the para nasal sinuses has vital importance and should be passably analyze before FESS.

\section{REFERENCES}

1. Vivek G, Khandelwal N. Imaging of paranasal sinuses. In: Niranjan K, Veena C, Arun KG, editors. Diagnostic radiology: neuroradiology including head and neck imaging. Jaypee Brothers Medical Publishers(P) LTD; 2010:366-86.

2. Zinreich SJ, Albayaram S, Benson ML, Oliverio PJ. The osteomeatal complex and functional endoscopic surgery. In: Som PM, Curtin HD, editors. Head and neck surgery. St Louis: Mosby Inc.; 2003:149-73.

3. J.S. Anthony, H.R. Harnsberger, S.B. Richard, Pneumatization of the paranasal sinuses: normal features of importance to the accurate interpretation of CT scans and MR imagesAJR, 160 (1993), pp. 1101-1104

4. G. Teatini, G. Simonetti, U. Salvolini, et al.Computed tomography of the ethmoid labyrinth and adjacent structures.Ann Otol Rhinol Laryngol, 96 (1987), pp. 239-250

5. K.A. Kasper Nasofrontal connections. A study based on one hundred consecutive dissections.Arch Otolaryngol, 23 (1936), pp. 322-344

6. C.M.N.R. Miranda, C.P.M. Maranhao, F.M.N.R. Arraes, et al.Anatomical variations paranasal sinuses at multislice computed tomography: what to look for Radiol Bras, 44 (2011), pp. 256-262

7. Asruddin, S.P.S. Yadav, R.K. Yadav, J. Singh Low dose CT in chronic sinusitis Indian J Otolaryngol, 52 (1999-2000), pp. $17-22$
8. H. Mamitha, N.M. Shamasunder, M.B. Bharathi, L.C. Prasanna Variations of osteomeatal complex and its applied anatomy: a CT scan study Indian J Sci Technol, 3 (2010), pp. $904-907$

9. D.G. Weinberger, V.K. Anand, M. Al-Rawi, H.I. Cheng, A.V. Messina Surgical anatomy and variations of the onodi cell Am J Rhinol, 10 (1996), pp. 365-370

10. A. Aramani, R.N. Karadi, S. Kumar Anatomical variation in osteaometal complex J Clin Diagn Res, 8 (2014), pp. 01-04

11. I. Perez-Pinas, J. Sabate, A. Carmona, C.J. Catalina Herrera, J. Jimenez-Castellanos Anatomical variations in the human paranasal sinus region studied by CT J Anat, 197 (2000), pp. 221-227

12. E. Scribano, G. Ascenti, F. Casio, S. Racchiusa, I. Salamone Computerized tomography in the evaluation of anatomic variations of the osteomeatal complex Radio Med (Torino), 86 (1993), pp. 195-199

13. W.E. Bolger, C.A. Butzin, D.S. Parsons Paranasal sinus bony anatomic variations and mucosal abnormalities: CT analysis for endoscopic sinus surgery Laryngoscope, 101 (1991), pp. 56-64

14. M.C. Delano, F.Y. Fun, S.J. Zinrich Relationship of the optic nerve to the posterior paranasal sinuses: a CT anatomic study Am J Neuroradiol, 17 (1996), pp. 669-675

15. S. Liu, Z. Wang, B. Zhou Related structures of the lateral sphenoid wall anatomy studies in CT and MRI Lin Chuang Er Bi Yan Hou Ke Za Zhi, 16 (2002), pp. 407-409

16. N. Basic, V. Basic, T. Jukic, et al. Computed tomographic imaging to determine the frequency of anatomical variations in pneumatization of the ethmoid bone Eur Arch Otorhinolaryngol, 256 (1999), pp. 69-71

17. P.M. Som, E.E. Park, T.P. Naidich, W. Lawson Crista galli pneumatization is an extension of the adjacent frontal sinuses AJNR Am J Neuroradiol, 30 (2009), pp. 31-33

18. H.D. Mohammad, Amir Daryani Evaluation of anatomic variants of paranasal sinuses Internet $\mathrm{J}$ Otorhinolaryngol, 1 (2007), pp. 1-5 